Aus dem Kaiser Wilhelm-Kreiskrankenhaus Kraupischken (Ostpreußen).

\title{
Seltene Komplikation einer diphtherischen Tracheal- und Larynxstenose.
}

Von Theo Cohnen, Leitender Arzt.

Bei Gelegenheit einer jetzt erloschenen Diphtherieepidemie im Spätherbst $1915 \mathrm{kam}$ ein Fall zur Beobachtung, der nicht ohne einiges Interesse sein dürfte.

Ein zweijähriges Mädchen, A. A., wird mit allen Symptomen einer schweren toxischen Diphtherie ins Haus gebracht. Allgemeinzustand äußerst schlecht, stärkste Dyspnoe und Zyanose, Puls beschleunigt und unregelmäßig, Bewußtsein getrübt. Die Atmung geht stoßweise mit lautem, krächzendem Pfeifen vor sich. Die Inspektion des Rachens ergibt mäßig geschwollene Tonsillen, die mit den typischen graugelben und festhaftenden Membranen belegt sind. Gewohnheitsgemäß wird intramuskulär eine hochwertige (2000 IE.) Seruminjektion verabreicht. Nach Verlauf von wenig mehr als einer Stunde hebt sich Puls und Allgemeinbefinden merklich. Indessen bleibt die Atmung nach wie vorher unverändert äußerst angestrengt, ohne aber eine $\mathrm{Zu}$ nahme der Larynxverengerung erkennen zu lassen. Wegen der drohenden Kohlensäureüberfüllung entschließe ich mich zur Tracheotomie in leichter Chloroformnarkose. Beim Eröffnen des Tracheallumens vermisse ich das charakteristische zischende Einströmen der Luft. Nur ein leises Hauchen gibt zu erkennen, daß wenig Luft den Weg zu den Bronchien findet. Der Versuch, eine Kanüle einzulegen, wird durch ein weiches Hindernis schon in der klaffend auseinandergezogenen Knorpelinzision durchkreuzt. Da die Not am höchsten ist, die Zyanose immer stärker wird, entschließe ich mich zu einer gewaltsamen Entfernung des unbekannten Hindernisses durch die Kornzange. Indessen wird der Entschluß durchkreuzt durch das Erscheinen eines männlichen Spulwurms von etwa $10 \mathrm{~cm}$ Länge, der, sich windend und krümmend, seinen schmierigen, graugelben Leib aus der Luftröhrenwunde bis etwa zur Hälfte hervorwälzt. Mit der Kornzange wird er vollends zutzge befördert.

Sofort strömt die Luft ungehindert durch die Trachea. Nach sekundenlangem Aussetzen der Atmung wechseln tiefe Atemzüge mit einzelnen Hustenstößen $a b$, wobei dünnflüssige, eitrige Massen und vereinzelte Membranfetzen herausbefördert werden. Einlegen einer Kanüle, Korrektur der Wunde. Nach eínigen Wochen wird das Kind als geheilt entlassen.

Dieses sicherlich nicht häufig vorkommende Ereignis dürfte dennoch bei der Beurteilung der Serumwirkung bei Diphtheriefällen der ländlichen Bevölkerung nicht ganz vergessen 'werden. Die vielen Diphtheriefälle, die im vergangenen Herbst in meine Hand kamen, lehrten mich die auch von anderen mitgeteilte Beobachtung, da $B$ die Besserung der Atemtätigkeit durch Lösung der Membranen fast stets der Hebung der Herzkraft und des Allgemeinzustandes vorausgeht oder doch wenigstens ihr nicht nachfolgt. Wenn, wie in dem mitgeteilten Falle, die Atmung nach der Injektion nach wie vor behindert bleibt, während sich die antitoxische Wirkung des Serums auf das Herz schon sicher zeigt, so dürfte in ländlichen Gegenden der Gedanke an ein lebendes Hindernis in den oberen Luftwegen nicht sogleich von der Hand gewiesen werden. Diese Vorsichtsmaßregel wird durch das häufige Erscheinen des Spulwurms in Mund und Nase ländlicher Kranken gerechtfertigt. In wenigen Monaten konnte ich bei relativ geringem Operationsmaterial in zwei Fällen den Wurm noch während der Narkose auf dem Operationstisch entfernen lassen; in einem anderen Falle, einer Nachamputation bei einer Sechzehnjährigen, ging der Wurm kurz nach dem Erwachen aus der Narkose durch den Brechakt ab. Ein bejahrter Nephritiker, dessen Magen und Darm durch eine mehrtägige Diätkur in Aufregung gebracht war, gab den Wurm ebenfalls durch den Mund von sich.

In allen Fällen liandelte es sich um mehr als $10 \mathrm{~cm}$ lange, männliche Exemplare von Ascaris Iumbricoides. 